\title{
Investigating KYNA production and kynurenergic manipulation on acute mouse brain slice preparations
}

Judit Herédi ${ }^{1}$, Edina Katalin Cseh $^{2}$, Anikó Magyariné Berkó ${ }^{1}$, Gábor Veres ${ }^{2}$, Dénes Zádori², József

Toldi ${ }^{1}$, Zsolt Kis ${ }^{1}$,László Vécsei ${ }^{2,3}$, Etsuro Ono ${ }^{4}$;Levente Gellért ${ }^{1,5, *}$

${ }^{1}$ Department of Physiology, Anatomy and Neuroscience, Faculty of Science and Informatics, University of Szeged, Közép Fasor 52., Szeged 6726, Hungary.

${ }^{2}$ Department of Neurology, Faculty of Medicine, University of Szeged, Semmelweis st.6, Szeged 6725 Hungary

${ }^{3}$ MTA-SZTE Neuroscience Research Group, University of Szeged, Semmelweis st. 6, Szeged 6725, Hungary.

${ }^{4}$ Department of Biomedicine, Graduate School of Medical Sciences, Kyushu University Fukuoka, Japan; Center of Biomedical Research, Research Center for Human Disease Modeling, Graduate School of Medical Sciences, Kyushu University Fukuoka, Japan.

${ }^{5}$ Institute of Physiology, University Medical Center of the Johannes Gutenberg University Mainz, Duesbergweg 6, D-55128 Mainz, Germany.

${ }^{*}$ Correspondence: Levente Gellért,

Institute of Physiology, University Medical Center of the Johannes Gutenberg University Mainz, Duesbergweg 6, D-55128 Mainz, Germany. 


\begin{abstract}
Manipulation of kynurenic acid (KYNA) level through kynurenine aminotransferase-2 (KAT2) inhibition with the aim of therapy in neuro-psychiatric diseses has been the subject of extensive recent research. Although mouse models are of particular importance, neither the basic mechanism of KYNA production and release nor the relevance of KAT-2 in the mouse brain has yet been clarified.

Using acute mouse brain slice preparations, we investigated the basal and L-kynurenine (LKYN) induced KYNA production and distribution between the extracellular and intracellular compartments. Furthermore, we evaluated the effect of specific KAT-2 inhibition with the irreversible inhibitor PF-04859989. To ascertain that the observed KYNA release is not a simple consequence of general cell degradation, we examined the structural and functional integrity of the brain tissue with biochemical, histological and electrophysiological tools.

We did not find relevant change in the viability of the brain tissue after several hours incubation time. HPLC measurements proved that mouse brain slices intensively produce and liberate KYNA to the extracellular compartment, while only a small proportion retained in the tissue both in the basal and L-KYN supplemented state. Finally, specific KAT-2 inhibition significantly reduced the extracellular KYNA content.

Taken together, these results provide important data about KYNA production and release, and in vitro evidence for the first time of the function of KAT-2 in the adult mouse brain. Our study extends investigations of KAT-2 manipulation to mice in a bid to fully understand the function; the final, future aim is to assign therapeutical kynurenergic manipulation strategies to humans.
\end{abstract}

Keywords: kynurenic acid, kynurenine aminotransferase-2 inhibition; acute slice viability; HPLC; immunohistochemistry; in vitro electrophysiology 


\section{Investigating KYNA production and kynurenergic manipulation on acute 2 mouse brain slice preparations}

3 Judit Herédi ${ }^{1}$, Edina Katalin $\mathrm{Cseh}^{2}$, Anikó Magyariné Berkó ${ }^{1}$, Gábor Veres ${ }^{2}$, Dénes Zádori², József

4 Toldi ${ }^{1}$, Zsolt Kis ${ }^{1}$, László Vécsei $^{2,3}$,Etsuro Ono ${ }^{4}$;Levente Gellért ${ }^{1, *}$

5

$6{ }^{1}$ Department of Physiology, Anatomy and Neuroscience, Faculty of Science and Informatics,

7 University of Szeged, Közép Fasor 52., Szeged 6726, Hungary.

$8 \quad{ }^{2}$ Department of Neurology, Faculty of Medicine, University of Szeged, Semmelweis st.6, Szeged 6725

9 Hungary

10

${ }^{3}$ MTA-SZTE Neuroscience Research Group, University of Szeged, Semmelweis st. 6, Szeged 6725, Hungary.

${ }^{4}$ Department of Biomedicine, Graduate School of Medical Sciences, Kyushu University Fukuoka, Japan; Center of Biomedical Research, Research Center for Human Disease Modeling, Graduate School of Medical Sciences, Kyushu University Fukuoka, Japan.

${ }^{*}$ Correspondence: Levente Gellért, Department of Physiology, Anatomy and Neuroscience, University of Szeged, Közép fasor 52, Szeged, H-6726, Hungary e-mail: gellert.levente1@gmail.com

Keywords: kynurenic acid, kynurenine aminotransferase-2 inhibition; acute slice viability; HPLC; immunohistochemistry; in vitro electrophysiology 


\section{Introduction}

Tryptophan (TRP) is catabolized mostly through the kynurenine pathway (KP) in the mammalian brain (Gal and Sherman 1980). Kynurenic acid (KYNA) is one of the neuroactive products of this metabolic route. KYNA is synthesized with the irreversible transamination of L-kynurenine (L-KYN), a reaction catalyzed by kynurenine aminotransferases (KATs) (Han et al., 2010a). KYNA exerts multiple effects on ligand-gated ion channels (Gal and Sherman, 1980, Birch et al., 1988, Prescott et al., 2006, Albuquerque and Schwarcz, 2013) and on the G-protein-coupled receptor 35 in the brain (Berlinguer-Palmini et al., 2013, Alkondon et al., 2015). Through these actions, KYNA can modulate neurotransmission systems (Zmarowski et al., 2009, Alexander et al., 2012, Banerjee et al., 2012a, Olsson et al., 2012). Indeed, the role of KYNA in neurophysiological and neuropathological processes has been the subject of extensive contemporary studies. The causal role of diversion of the KP has been proposed in several neurodegenerative and neuropsychiatric disorders (e.g. Alzheimer's disease, Parkinson's disease, Huntington's disease, cerebral ischemia, depression, and schizophrenia) (Vecsei et al., 2013). Thus, kynurenergic manipulation with the aim of therapy has also been proposed (Amaral et al., 2013).

To date, cross-species differences of the relevance and regulation of brain KP function and KYNA production are not fully clarified. The majority of the experimental data concerns the rat kynurenine system, however, mouse models are of particular importance as well (Rosenthal and Brown, 2007).

Yet, there is neither detailed study about the mechanism and regulation of KYNA release from cells in the mouse brain parenchyma, nor information about the function of relevant KAT enzymes of the KP. For instance, the importance of kynurenine aminotransferase-2 (KAT-2) in the rat and human brain is unequivocal, the relevance of KAT-2 in the mouse brain is, however, controversial (Han et al., 2010a).

For describing the kynurenine system in model animals and investigating the effect of kynurenergic manipulation, in vitro models are essential and complement in vivo studies. To this end, acute brain slice preparations provide many advantages over in vivo experiments (Cho et al., 2007, Lein et al., 2011). Previously, KYNA production and release to the extracellular compartment upon L-KYN exposure was described in cortical (Turski et al., 1989, Hodgkins et al., 1999) and in hippocampal rat brain slices (Scharfman et al., 1999, Alkondon et al., 2011). However, there is no data about KYNA production of acute mouse brain slice preparations. Furthermore, these studies did not concern the acute slice viability, a factor, which can strongly influence the KYNA production and release. 
The present study was designed to estimate the KYNA production and release of acute mouse brain slices and to assess the effect of the specific KAT-2 inhibitor PF-04859989 on KYNA production in vitro.

Basing on literature data we presumed that the concentration of KYNA released into the extracellular space falls into the picomolar or low nanomolar range (Schwieler et al., 2006). To ensure a measurable concentration of KYNA for HPLC assessments we incubated our slices in a low bulk volume of artificial cerebrospinal fluid (aCSF) (that is approx. $6 \mathrm{ml}$ of $\mathrm{aCSF} / 100 \mathrm{mg}$ wet weight brain tissue) under continuous carbogenation, but without perfusion. In previous studies KYNA increase and release could be measured 2-4hours after L-KYN administration in rat (Turski et al., 1989, Swartz et al., 1990). Results of our pilot experiments are in line with that finding (unpublished data). Therefore, we decided to incubate brain slices for 4-6 hours. Incubation of acute slices inherently initiates progressive damage in the tissue (Fukuda et al., 1995). It is therefore possible that metabolic properties and integrity of cells involved in KYNA production and release might alter during several hours of incubation. In order to characterize the after-incubation viability of the brain tissue we performed histological observations, biochemical and electrophysiological characterization of the slices. To investigate the extra/intracellular distribution of basal KYNA, we compared the KYNA content in the tissue with that liberated into the extracellular space. Then, we wanted to know if we could induce de novo KYNA production with the administration of the KYNA precursor L-KYN. Finally, we investigated the effect of the KAT-2 inhibitor on the L-KYN-induced KYNA release.

Investigating tissue viability, we found a slight alteration in some of the observed tissue viability measures. However, the slices showed no anatomical or functional abnormalities, so tissue integrity was preserved.

Regarding KYNA production, we found that in the course of 4hours incubation slices readily release both basal and de novo produced KYNA into the supernatant aCSF, whereas only a negligible fraction of total KYNA is retained in the tissue. The KAT-2 inhibitor, however, conspicuously decreased KYNA release. 


\section{Experimental Procedures}

\subsection{Animals}

8-12 weeks old male $C 57 \mathrm{Bl} / 6$ mice obtained from The National Institute of Oncology (Budapest, Hungary) were used $(\mathrm{n}=30)$ for the experiments. Animals were kept under controlled laboratory conditions and had free access to food and water. All experiments were in compliance with the guidelines of the European Communities Council Directives (2010/63/EU) and the Hungarian Act for the Protection of Animals in Research (XXVIII.tv. $32 . \S)$.

\subsection{Acute slice preparation}

Animals were anesthetized with isoflurane (3\%) followed by decapitation (NEMI Guillotine; Braintree Scientific, Inc.). The brain was rapidly removed and submerged in ice-cold aCSF (pH 7.4) composed of (in mM): 234 sucrose, $3.5 \mathrm{KCl}, 1 \mathrm{NaH}_{2} \mathrm{PO}_{4}, 24 \mathrm{NaHCO}_{3}, 1 \mathrm{CaCl}_{2}, 3$ $\mathrm{MgSO}_{4}$ and 10 D-glucose (Sigma Aldrich) and oxygenated with 95\% $\mathrm{O}_{2}$ and 5\% $\mathrm{CO}_{2} .350$ $\mu \mathrm{m}$ thick sections were obtained with a vibratome (Leica VT1200S, Germany); the two hemispheres were dissected and transferred to a holding chamber. Slices were allowed to recover for $30 \mathrm{~min}$ in aCSF (pH 7.4) containing (in $\mathrm{mM}$ ): $130 \mathrm{NaCl}, 3.5 \mathrm{KCl}, 1 \mathrm{NaH}_{2} \mathrm{PO}_{4}, 24$ $\mathrm{NaHCO}_{3}, 1.5 \mathrm{CaCl}_{2}, 3 \mathrm{MgSO}_{4}$ and 10 D-glucose

\subsection{Small volume incubation of brain slices}

After $30 \mathrm{~min}$ recovering, one hemisphere of the 6 coronal slices were transferred to the incubation chambers containing a low bulk volume of aCSF (appr. $6 \mathrm{ml}$ of aCSF/6 half coronal slice), placed on a closed-loop temperature controller pad (TMP-5b, Supertech Instruments UK Ltd.) at $30{ }^{\circ} \mathrm{C}$ to reach optimal temperature for KAT function (Banerjee et al., 2012b) (SV condition hereafter). The aCSF was continuously bubbled with $95 \% \mathrm{O}_{2}$ and $5 \% \mathrm{CO}_{2}$ but was not circulated during the incubation.

For comparison of tissue viability of slices incubated in SV condition or in standard condition, we performed the same battery of experiments on the corresponding 6 half coronal slices kept under standard conditions (high bulk volume of aCSF; $\approx 200 \mathrm{ml} / 6$ half coronal slice) at $20^{\circ} \mathrm{C}$ ( $\mathbf{L V}$ condition hereafter). Through this LV slice incubation routine we could perform stable field excitatory postsynaptic potentials (fEPSP) recordings after $8 \mathrm{~h}$ incubation, therefore, this condition was used as an adequate control for assessing tissue viability under SV condition. 
After evaluating tissue viability, we studied KYNA production and kynurenergic manipulation in the SV condition. $10 \mu \mathrm{M}$ L-KYN (Sigma Aldrich) and $5 \mu \mathrm{M}$ KAT-2 inhibitor PF-04859989 were dissolved in aCSF. The scheme of the protocol used in this study is illustrated in Supp. Fig. 1.

At the end of the incubations, the supernatants were collected and stored at $-80{ }^{\circ} \mathrm{C}$ for further biochemical analysis. One portion of the slices were placed in 4\% paraformaldehyde (PFA) and fixed overnight for histological studies, whereas the remaining slices were immediately frozen in liquid nitrogen and stored at $-80{ }^{\circ} \mathrm{C}$ for Western blotting (see in the supplement).

\subsection{Electrophysiology}

After $4 \mathrm{~h}$ incubation in the LV or SV condition, the slices were transferred to an interface recording chamber and superfused with aCSF containing (in $\mathrm{mM}$ ): $130 \mathrm{NaCl}, 3.5 \mathrm{KCl}, 1$ $\mathrm{NaH} 2 \mathrm{PO}_{4}, 24 \mathrm{NaHCO}_{3}, 3 \mathrm{CaCl}_{2}, 1.5 \mathrm{MgSO}_{4}$ and 10 D-glucose. The temperature $\left(32{ }^{\circ} \mathrm{C}\right)$ and flow rate $(2 \mathrm{ml} / \mathrm{min})$ of the aCSF were continuously controlled. Baseline synaptic function of the tissue was tested with input-output (I/O) curve recordings on the CA3-CA1 cell synapses in the hippocampus. Schaffer collaterals were stimulated at $0,05 \mathrm{~Hz}$ using a concentric bipolar stainless steel electrode (Neuronelektrod Ltd, Hungary). fEPSPs were recorded from the stratum radiatum of $\mathrm{CA} 1$ region with 1,5-3 mOhm resistance glass microelectrodes.

Potentials were amplified and filtered with WPI AMP-04 amplifier and digitalized with Axon Digidata 1320A. Recordings were monitored and saved with Axoscope 10.0 (Molecular Devices Corporation, USA). Data were analyzed with Clampfit 10.6 (Molecular Devices, USA) and OriginPro 8.6 (OriginLab Corporation, USA) softwares. In the course of I/O curve recordings to define the minimal stimulus we decreased the stimulus intensity until minimal but unequivocal fEPSP was evoked. The stimulus was then increased in $5 \mu \mathrm{A}$ increments. We collected five responses and averaged at each increment. We continued to increase the stimulus intensity until fEPSP response had saturated. fEPSP slope values were normalized and averaged across all slices in each group and plotted as a function of normalized stimulus intensity to construct $\mathrm{I} / \mathrm{O}$ curves.

\subsection{Histology}

Fixed brain slices were cryoprotected with sucrose solution and $30 \mu \mathrm{m}$ thick sections were cut with a freezing microtome (Reichert-Jung 1206).

Immunohistochemistry: Free-floating sections were washed in PBT, incubated in 1\% NDS and exposed to the primary antibody (mouse anti-NeuN, 1:4000, Millipore) overnight at $4{ }^{\circ} \mathrm{C}$. 
Next day, they were incubated in the appropriate secondary antibody (1:500; Jackson 148 ImmunoResearch) at room temperature. Primary and secondary antibody were diluted in 0.1 M PBT containing 1\% NDS. Negative control was prepared from sections incubated without the primary antibody. The sections were coverslipped with antifade mounting medium

151

152 (ProLong® Gold, Life Technologies).

Cresyl violet staining: We performed cresyl violet staining for morphological observations after different incubation conditions and time. Sections were rehydrated with descending grades of alcohol and stained with cresyl violet staining solution for $5 \mathrm{~min}$. After staining, samples were passed through ascending alcohol solutions and immersed in xylene for $5 \mathrm{~min}$. Sections were coverslipped with Entallan ${ }$.

All photomicrographs were obtained with an Olympus BX51 microscope fitted with a DP70 digital imaging system.

\subsection{Lactate dehydrogenase (LDH) assay}

For evaluating tissue viability we performed LDH activity assay on supernatant samples collected after $30 \mathrm{~min}, 4 \mathrm{~h}$ and $6 \mathrm{~h}$ incubation time. As positive control for LDH release we permeabilized the cell membrane with Triton X-100 $340 \mathrm{~nm}$ and $37^{\circ} \mathrm{C}$ using an LDH activity assay kit (Diagnosticum Ltd, Hungary, 46461) on a BioLis 24i Premium system (Siemens). LDH activity was expressed as U/1/100 mg tissue.

\subsection{Hexokinase (HK) assay}

Glucose content was measured by HK activity assay on supernatant samples collected after 30 min, $4 \mathrm{~h}$ and $6 \mathrm{~h}$ incubation time. HK activity was measured at $340 \mathrm{~nm}$ and $37{ }^{\circ} \mathrm{C}$ using a twostep Glu HK activity assay kit (Diagnosticum Ltd, Hungary, 47361) on a BioLis 24i Premium system (Siemens).

\subsection{High performance liquid chromatography (HPLC)}

The brain slices were weighed and then homogenized for $30 \mathrm{~s}$ in $250 \mathrm{ml}$ ice-cold solution, containing trifluoroacetic acid $(0.1 \% \mathrm{v} / \mathrm{v})$ and $2 \mu \mathrm{M}$ 3-nitro-L-tyrosine (3-NLT, as internal standard). The homogenate was centrifuged at $12000 \mathrm{RPM}$ for $10 \mathrm{~min}$ at $4{ }^{\circ} \mathrm{C}$. The supernatants were stored at $-80^{\circ} \mathrm{C}$ until further analysis. Similar procedure was applied for the aCSF samples, briefly, $250 \mu \mathrm{L}$ aCSF was treated with $50 \mu 1$ of above-mentioned solution, and then centrifuged under the same circumstances as the brain tissues. The resulting supernatants were measured with an Agilent 1100 HPLC system (Agilent Technologies, Santa Clara, CA, USA) combined with a fluorescence (FLD) and a UV detector. For the determination of 
KYNA, the excitation and emission wavelengths of FLD were set at $344 \mathrm{~nm}$ and $398 \mathrm{~nm}$, 180 whereas the UV detector was set at $365 \mathrm{~nm}$ for the determination of 3-NLT. Chromatographic separations were performed on an a Kinetex C18 column, 150 x $4.6 \mathrm{~mm}$ I.D., $5 \mu \mathrm{m}$ particle size (Phenomenex Inc., Torrance, CA, USA) preceded by Security Guard pre-column C18, 4 x 3.0 mmI.D., $5 \mu \mathrm{m}$ particle size (Phenomenex Inc., Torrance, CA, USA) with a mobile phase composition of $0.2 \mathrm{M}$ zinc acetate $/ \mathrm{ACN}=95 / 5 \mathrm{v} / \mathrm{v} \%$, in which $\mathrm{pH}$ was adjusted at 6.2 with acetic acid, applying isocratic elution. The flow rate was $1.2 \mathrm{ml} / \mathrm{min}$ and the injection volume was $50 \mu \mathrm{L}$. As for the method validation, following parameters are reported, briefly, regarding KYNA in tissue and aCSF. The LOD and LOQ in tissue and aCSF samples were 1 and $3.75 \mathrm{nM}$, respectively. With regard to precision, the relative standard deviation was $\leq$ $2.2 \%$. The recoveries in tissue and aCSF samples ranged from $103 \%$ to $108 \%$ and $81 \%$ to $91 \%$, respectively.

\subsection{Data analysis and Statistics}

192 KYNA content was calculated from the concentration values measured by HPLC and data 193 were normalized to the tissue weight. In the case of the aCSF, values represented KYNA content released by $100 \mathrm{mg}$ tissue. LDH release and glucose consumption data were similarly normalized to $100 \mathrm{mg}$ tissue.

All statistical computations were carried out with the IBM SPSS Statistics software (version 20.). Homogeneity of variance across groups was tested with the Levene's Test of Equality of Error Variances. Distribution of the data was tested with the-Shapiro-Wilk test of normality. Statistical significance was calculated with the GLM univariate model. If assumption of variance homogeneity was violated, Kruskal-Wallis Test was used. For repeated measures of the I/O curve recordings, General Linear Model Repeated Measures method was applied. 


\section{Results}

\subsection{Glucose consumption}

To our best knowledge, there is no literature data about the minimal bulk volume of aCSF in which acute mouse brain slices can function quasi normally for hours. Therefore, first, we asked if the glucose availability in the aCSF under SV condition exceeds the nutrition demand of the slices.

Glucose consumption measurement proved that glucose availability gradually decreased during the incubation. Glucose concentration was already dropped after $30 \mathrm{~min}$, however, the decrease was not statistically significant $(\mathrm{F}=4,281 ; \mathrm{p}=0,072$; Partial Eta Squared: 0,349$)$. $4 \mathrm{~h}$ incubation, however, resulted in a significant decrease of aCSF glucose content $(F=20,304$; $\mathrm{p}=0,002$; Partial Eta Squared: 0,717) compared to original level (Fig. 1). It was further declined during the $6 \mathrm{~h}$ incubation time (data not depicted).

\subsection{Viability of acute brain slices $-\mathrm{LDH}$ release}

A characteristic sign of the perturbation of normal cellular function is the loss of cell membrane integrity and the concomitant increase of membrane permeability (Cho et al., 2007). Therefore, alteration in LDH release to the extracellular space is a sensitive measure of cell viability. Under SV condition LDH release was continuously increasing in the aCSF during $30 \min (Z=16,910 ; p=0,959), 4 h(Z=16,910 ; p=0,030)$ and also $6 \mathrm{~h}$ incubation (data not depicted), compared to the initial state. However, Triton X-100 treatment resulted in $\mathrm{a} \approx 14$ fold increase of LDH in the aCSF after $4 \mathrm{~h}$ incubation $(Z=16,910 ; p=0,001)$ (Fig. 2). This indicates that the cell membrane integrity is largely preserved in the course of $4 \mathrm{~h}$ incubation. The observed KYNA release is not the simple consequence of disrupted membrane integrity (see below).

\subsection{Histological observations}

For the histological examination of tissue state we performed NeuN immunolabelling and cresyl violet staining. There was no visible tissue damage in the vulnerable CA1 subregion of the dorsal hippocampus. CA1 pyramidal cell shape and size appeared normal after $4 \mathrm{~h}$ incubation (Fig. 3). However, the structural integrity of pyramidal cells in CA1 was not completely preserved after $6 \mathrm{~h}$ incubation. Compared to the control group, shrunken and deformed pyramidal cells emerged (visual observation). 


\subsection{Synaptic properties of acute brain slices - I/O curves}

Basal glutamatergic synaptic properties were tested by means of fEPSP recording, expressed against gradually increased stimulating intensity in certain groups. There was no significant difference between slices recorded immediately after post-slicing recovery period (30 min.), or incubated under LV condition for 4hours and under SV conditions, respectively $(F=0.793$; $\mathrm{p}=0,465$; Partial Eta Squared: 0,064). This result indicates that, the baseline synaptic function of the brain tissue was preserved after 4h SV incubation (Fig. 4).

Considering the decreased glucose availability and increased LDH release, furthermore the visually observed tissue damage after $6 \mathrm{~h}$, the $4 \mathrm{~h}$ long incubation duration was considered to be the most suitable for KYNA measurement.

\subsection{KYNA production in mouse brain slices}

To examine whether mouse brain slices liberate endogenous and de novo produced KYNA upon L-kynurenine administration during $4 \mathrm{~h}$ long incubation period we performed HPLC measurements from brain tissue homogenate and from incubating aCSF.

Without L-KYN administration 7.01 $\pm 2.03 \mathrm{ng}$ basal KYNA content could be measured from the aCSF and $0.22 \pm 0.07 \mathrm{ng}$ from the brain tissue homogenate. In contrast, as a result of $10 \mu \mathrm{M}$ L-KYN administration we found a 6.3 fold increase in the aCSF $(44.56 \pm 6,99 \mathrm{ng})(\mathrm{Z}=6,818$; $\mathrm{p}=0,009)$ and a 3.8 fold increase in the tissue $(0.85 \pm 0.21 \mathrm{ng})$ KYNA content (Fig. 5). No considerable KYNA elevation could be observed in the course of $6 \mathrm{~h}$ incubation compared to the $4 \mathrm{~h}$ incubation (data not depicted).

In conclusion, $\approx 97 \%$ of the total KYNA content was released to the extracellular compartment ( $\mathrm{aCSF}$ ), whereas only $\approx 3 \%$ remained in the tissue under both conditions (Supp. Fig. 2)

\subsection{Effect of KAT-2 inhibitor PF-04859989 on de novo KYNA release}

In the next series of experiments we incubated acute slices in the presence of $10 \mu \mathrm{M} \mathrm{L}-\mathrm{KYN}$, with or without PF-04859989 in a concentration of $5 \mu \mathrm{M}$. KYNA content of the aCSF was measured after $4 \mathrm{~h}$ incubation. Similar to former results high KYNA content could be measured in the L-KYN group $(55.19 \pm 6.45 \mathrm{ng})$. Addition of the inhibitor resulted in a significant decrease of the released KYNA in the aCSF by almost $40 \%(34.5 \pm 6.93 \mathrm{ng}$; $\mathrm{F}=23,868 ; \mathrm{p}=0,001$; Partial Eta Squared: 0,749) (Fig. 6). 
The implication of kynurenine metabolites in several brain disorders (e.g. schizophrenia, Alzheimer's disease, depression, migraine) shifted much attention to the manipulation of the $\mathrm{KP}$ in recent years (Dounay et al., 2015). The KP of tryptophan catabolism is present in many mammalian species (Moroni et al., 1988). Concomitantly, the neuromodulatory metabolites of this route are produced and function, making model animals suitable for extrapolating the effects of kynurenergic manipulation in humans. However, there are prominent differences among mammalian species regarding the kynurenine system (Moroni et al., 1988, Fujigaki et al., 1998), complicating further the understanding of the physiological and pathological role of the KP.

The physiological concentration of KYNA is different in model animals and in humans. The lowest basal KYNA level is found in the mouse brain, whereas it is the highest in the human neocortex (Moroni et al., 1988). The KYNA synthesizing enzyme isoforms have also a different role in different species. In the human and rat brain KAT-2 plays the major role in KYNA production, whereas in mice kynurenine aminotransferase-4 (KAT-4) was supposed to be the main KYNA synthesizing enzyme (Alkondon et al., 2004, Guidetti et al., 2007). However, KAT-2 null mutation resulted in the decrease of extracellular KYNA level in transgenic mice (Potter et al., 2010). Therefore, comparative characterization of the kynurenine catabolism in different model species is essential before assigning therapeutical kynurenergic manipulation strategies in humans.

Investigating the KP in vitro is of particular importance. In contrast to in vivo assays, acute brain slice preparations provide the possibility to exclude the perturbation effect of the peripheral KP function, while replicating or even changing many aspects of the in vivo context. A large panel of pharmacological interventions can be efficiently evaluated; furthermore, endogenous factors influencing brain KYNA production might also be easily clarified.

\subsection{The after-incubation state of mouse brain slice preparations}

One of the major limitations of acute brain slice models is the viability of nervous tissue, which endures on average for $\approx 6-8$ hours (Buskila et al., 2014). However, there are specific brain areas (e.g. dorsal hippocampus) and cell populations where this window is even narrower ( $\approx 4$ hours) (Fukuda et al., 1995). To ascertain that KYNA release is not an uncontrolled function of a deteriorated brain tissue, we examined the after-incubation 
viability. After $4 \mathrm{~h}$ and $6 \mathrm{~h}$ incubations in the SV aCSF, respectively, we observed slight alterations in tissue integrity and function.

The change of cell membrane integrity was evaluated by measuring the cytosolic LDH released into the aCSF. LDH could be measured and was continuously increasing during the incubation time, a phenomenon that verifies the limited and relatively narrow working window with acute brain slices. The considerably higher LDH content of the supernatant aCSF after membrane permeabilization indicates that after $4 \mathrm{~h}$ incubation membrane integrity of the nervous tissue is largely preserved.

Changes in glucose consumption and glucose availability we estimated with a glucose hexokinase assay. We found that the available glucose was gradually decreased in the course of $4 \mathrm{~h}$ and $6 \mathrm{~h}$ incubation (not depicted). Although, continuous aCSF LDH level increase suggests a gradual loss of membrane integrity, decrease of glucose availability in the course of $4 \mathrm{~h}$ and $6 \mathrm{~h}$ incubation is possible only if, the nervous tissue actively metabolizes glucose. In the nervous tissue both astrocytic and neuronal glucose up-take is possible through facilitative membrane glucose transporters (Chuquet et al., 2010, Lundgaard et al., 2015). A shift toward one of these mechanisms we did not estimate, however we may conclude a generally preserved glucose up-take, consumption-machinery and functioning brain tissue.

Although the selective vulnerability of the CA1 region of the hippocampus to a variety of insults (e.g. excitotoxicity, cerebral ischemia) has been reported (Davolio and Greenamyre, 1995, Kovalenko et al., 2006) we observed no visible tissue damage in this brain area.

Furthermore, Schaffer-collateral CA1 pyramidal cell synapses were equally functional in the compared groups. There was no significant difference between slices recorded immediately after post-slicing recovery period (30 min.), or incubated under LV condition for thours and under SV conditions, respectively. This indicates that functional integrity of vulnerable region was largely preserved during a $4 \mathrm{~h} \mathrm{SV}$ incubation.

\subsection{Basal and de novo KYNA production in mouse brain slices}

Our first and basic question was, whether KYNA production can be measured and elevated in mouse brain slice preparations. To increase KYNA production L-KYN concentration $(10 \mu \mathrm{M})$ was chosen on the basis of previous studies on slice preparations (Urbanska et al., 2000, Okuno et al., 2011). Similar to rat brain slices (Alkondon et al., 2011), mouse brain slices could produce KYNA upon L-KYN exposure and liberate newly formed KYNA to the extracellular space after $4 \mathrm{~h}$ incubation (See Fig. 5.). In trial experiments we measured KYNA production after $2 \mathrm{~h}$ incubation, but there was no sufficient KYNA increase in the L-KYN 
treated group on which the inhibition of KYNA synthesis could reliably be studied (not depicted). Therefore, $4 \mathrm{~h}$ long incubation was necessary to examine KYNA production and the effect of KAT-2 inhibition.

It is important to note that, extending the extracellular space of the acute slices with the incubating aCSF (approx. $100 \mathrm{mg}$ wet weight brain tissue/6ml aCSF) results in a considerably smaller intracellular/extracellular volume ratio than found in the intact mouse brain (approx. 500mg wet weight brain tissue/0,04ml CSF (Artru, 1993). That difference means a steep concentration gradient and driving force toward the aCSF for any released molecules. After $4 \mathrm{~h}$ incubation the amount of the released KYNA was more than 30 times higher than that retained in the tissue (See Supp. Fig. 2.). This release mechanism of KYNA is still unknown and should also be investigated in future work. Nevertheless, a high local KYNA concentration might be reached upon L-KYN treatment in the close apposition of the KYNA release sites.

It is important to note that our results regarding KYNA production may not reflect completely the in vivo mechanisms. The brain-to-blood elimination of brain KYNA through probenecidsensitive organic acid transport is continuous in vivo (Miller et al., 1992), however, the ratio of elimination in the mice is not described. Furthermore, the composition of aCSF differs in several aspects from the in vivo physiological extracellular milieu. For instance, there are no amino acids in the aCSF (e.g. aspartate, tryptophan), which can negatively impact the activity of the KAT isoenzymes (Han et al., 2010b). The applied incubation temperature was lower than physiological, but higher temperature curtails the lifespan of acute slices as a consequence of bacterial growth and cellular metabolism (Buskila et al., 2014). Lower temperature slows down these adverse processes and prolong the time period during which the slices can be kept functional. Beyond tissue viability aspects, and in vitro electrophysiological routines we chose $30{ }^{\circ} \mathrm{C}$ for incubation basing on the paper of Banerjee et al. (2012), where this temperature was used as an optimal temperature for KAT-2 (Banerjee et al., 2012). These differences may lead to altered KAT activity and to a modified production of KYNA. However, we did not find altered KAT-2 expression level of the samples incubated under SV condition $(F=0.000 ; p=0.989$; Partial Eta Squared: 0.000), therefore a quasi normally KYNA production can be suggested (Supp. Fig. 3).

The $\approx 6.3$ fold elevation in aCSF KYNA content by this small amount of tissue after L-KYN addition indicates a high KAT capacity. Previously it has been shown on purified KAT preparation from rat liver that KATs have high capacity and $\mathrm{Km}$ value $(\sim 1 \mathrm{mM})$ for L-KYN 
(Bender and McCreanor, 1985). Indeed, KYNA production in the rat brain was saturable only at high L-KYN $(\approx 1 \mathrm{mM})$ concentration (Turski et al., 1989), which is concordant with our findings.

In conclusion, mouse brain tissue intensively liberates endogenous and de novo synthesized KYNA into the extracellular milieu in vitro, whereas the retained KYNA in the tissue is negligible.

\subsection{Effect of KAT-2 inhibitor PF-04859989 on de novo KYNA release}

The advent of highly specific KAT-2 inhibitors opened new perspectives in clarifying KP function in rodents (Dounay et al., 2012, Nematollahi et al., 2016). However, no pharmacological experiment has yet targeted the mouse KAT-2 function, probably because of its proposed irrelevance (Guidetti et al., 2007). In our previous anatomical study, we found prominent KAT-2 immunopositivity in astrocytes and in GABAergic cells in the adult mouse brain (Heredi et al., 2017). We therefore hypothesized that KAT-2 has a specific role in mouse brain KYNA function. Because of the low basal KYNA content of the tissue homogenate and that of the aCSF (usually close to the detection limit of HPLC), we estimated the effect of the inhibitor on the KYN induced de novo KYNA production.

Applying the highly specific KAT-2 inhibitor PF-04859989 in a similar concentration, which was found in the rat CSF after parenteral application (Dounay et al., 2012), resulted in a decrease of de novo KYNA production by almost $40 \%$. Although, this is higher than has previously been reported using alternative methods, KYNA production was not completely abolished following KAT-2 inhibition; $60 \%$ of total KAT activity remained. This indicates that, in a whole other KAT enzymes make a greater contribution in the mouse brain, however, it does not exclude the important role of mouse KAT-2. Indeed, an incomplete inhibition of KAT activity is more suitable in the experimental models of therapeutical KYNA level reduction. Our results indicate that the investigation of the effects of pharmacological KAT-2 inhibition should be extended to mouse models, which was largely neglected in this relation.

\section{Acknowledgments}

Thanks are due to Matthew Higginson for grammar proofreading.

\section{Funding}

This study was supported by grant GINOP 2.3.2-15-2016-00034 and co-financed by EFOP3.6.1-16-2016-00008 grant and grant by MTA-SZTE Neuroscience Research group. LG, JH, 
396 JT, ZsK, LV, EO were fellows in the JSPS-HAS mobility scholarship program (NKM397 48/2017). Dénes Zádori was supported by the János Bolyai Scholarship of the Hungarian 398 Academy of Sciences.

399

\section{Conflict of interest}

401 The authors declare no competing financial interests. All co-author agree with the submission 402 of this form of the manuscript.

403

404

405 
Albuquerque EX, Schwarcz R (2013) Kynurenic acid as an antagonist of alpha7 nicotinic acetylcholine receptors in the brain: facts and challenges. Biochem Pharmacol 85:1027-1032.

Alexander KS, Wu HQ, Schwarcz R, Bruno JP (2012) Acute elevations of brain kynurenic acid impair cognitive flexibility: normalization by the alpha7 positive modulator galantamine. Psychopharmacology (Berl) 220:627-637.

Alkondon M, Pereira EF, Eisenberg HM, Kajii Y, Schwarcz R, Albuquerque EX (2011) Age dependency of inhibition of alpha7 nicotinic receptors and tonically active $\mathrm{N}$-methyl-D-aspartate receptors by endogenously produced kynurenic acid in the brain. J Pharmacol Exp Ther 337:572-582.

Alkondon M, Pereira EF, Todd SW, Randall WR, Lane MV, Albuquerque EX (2015) Functional Gprotein-coupled receptor 35 is expressed by neurons in the CA1 field of the hippocampus. Biochem Pharmacol 93:506-518.

Alkondon M, Pereira EF, Yu P, Arruda EZ, Almeida LE, Guidetti P, Fawcett WP, Sapko MT, Randall WR, Schwarcz R, Tagle DA, Albuquerque EX (2004) Targeted deletion of the kynurenine aminotransferase ii gene reveals a critical role of endogenous kynurenic acid in the regulation of synaptic transmission via alpha7 nicotinic receptors in the hippocampus. J Neurosci 24:4635-4648.

Amaral M, Outeiro TF, Scrutton NS, Giorgini F (2013) The causative role and therapeutic potential of the kynurenine pathway in neurodegenerative disease. Journal of molecular medicine 91:705-713.

Artru A.A. (1993) Cerebrospinal Fluid: Physiology and Pharmacology. In: Sperry R.J., Johnson J.O., Stanley T.H. (eds) Anesthesia and the Central Nervous System. Developments in Critical Care Medicine and Anesthesiology, vol 28. Springer, Dordrecht

Banerjee J, Alkondon M, Albuquerque EX (2012a) Kynurenic acid inhibits glutamatergic transmission to CA1 pyramidal neurons via alpha7 nAChR-dependent and -independent mechanisms. Biochem Pharmacol 84:1078-1087.

Banerjee J, Alkondon M, Pereira EF, Albuquerque EX (2012b) Regulation of GABAergic inputs to CA1 pyramidal neurons by nicotinic receptors and kynurenic acid. J Pharmacol Exp Ther 341:500509.

Bender DA, McCreanor GM (1985) Kynurenine hydroxylase: a potential rate-limiting enzyme in tryptophan metabolism. Biochem Soc Trans 13:441-443.

Berlinguer-Palmini R, Masi A, Narducci R, Cavone L, Maratea D, Cozzi A, Sili M, Moroni F, Mannaioni G (2013) GPR35 activation reduces Ca2+ transients and contributes to the kynurenic aciddependent reduction of synaptic activity at CA3-CA1 synapses. PLoS One 8:e82180.

Birch PJ, Grossman CJ, Hayes AG (1988) Kynurenic acid antagonises responses to NMDA via an action at the strychnine-insensitive glycine receptor. Eur J Pharmacol 154:85-87.

Buskila Y, Breen PP, Tapson J, van Schaik A, Barton M, Morley JW (2014) Extending the viability of acute brain slices. Scientific reports 4:5309.

Cho S, Wood A, Bowlby MR (2007) Brain slices as models for neurodegenerative disease and screening platforms to identify novel therapeutics. Curr Neuropharmacol 5:19-33.

Chuquet J, Quilichini P, Nimchinsky EA, Buzsaki G (2010) Predominant enhancement of glucose uptake in astrocytes versus neurons during activation of the somatosensory cortex. J Neurosci 30:15298-15303.

Davolio C, Greenamyre JT (1995) Selective vulnerability of the CA1 region of hippocampus to the indirect excitotoxic effects of malonic acid. Neurosci Lett 192:29-32.

Dounay AB, Anderson M, Bechle BM, Campbell BM, Claffey MM, Evdokimov A, Evrard E, Fonseca KR, Gan X, Ghosh S, Hayward MM, Horner W, Kim JY, McAllister LA, Pandit J, Paradis V, Parikh VD, Reese MR, Rong S, Salafia MA, Schuyten K, Strick CA, Tuttle JB, Valentine J, Wang H, Zawadzke LE, Verhoest PR (2012) Discovery of Brain-Penetrant, Irreversible Kynurenine Aminotransferase II Inhibitors for Schizophrenia. ACS medicinal chemistry letters 3:187-192. 
Dounay AB, Tuttle JB, Verhoest PR (2015) Challenges and Opportunities in the Discovery of New Therapeutics Targeting the Kynurenine Pathway. J Med Chem 58:8762-8782.

Fujigaki S, Saito K, Takemura M, Fujii H, Wada H, Noma A, Seishima M (1998) Species differences in Ltryptophan-kynurenine pathway metabolism: quantification of anthranilic acid and its related enzymes. Arch Biochem Biophys 358:329-335.

Fukuda A, Czurko A, Hida H, Muramatsu K, Lenard L, Nishino H (1995) Appearance of deteriorated neurons on regionally different time tables in rat brain thin slices maintained in physiological condition. Neurosci Lett 184:13-16.

Gal EM, Sherman AD (1980) L-kynurenine: its synthesis and possible regulatory function in brain. Neurochem Res 5:223-239.

Guidetti P, Amori L, Sapko MT, Okuno E, Schwarcz R (2007) Mitochondrial aspartate aminotransferase: a third kynurenate-producing enzyme in the mammalian brain. J Neurochem 102:103-111.

Han Q, Cai T, Tagle DA, Li J (2010a) Structure, expression, and function of kynurenine aminotransferases in human and rodent brains. Cellular and molecular life sciences : CMLS 67:353-368.

Han Q, Cai T, Tagle DA, Li J (2010b) Thermal stability, pH dependence and inhibition of four murine kynurenine aminotransferases. BMC Biochem 11:19.

Heredi J, Berko AM, Jankovics F, Iwamori T, Iwamori N, Ono E, Horvath S, Kis Z, Toldi J, Vecsei L, Gellert L (2017) Astrocytic and neuronal localization of kynurenine aminotransferase-2 in the adult mouse brain. Brain Struct Funct 222:1663-1672.

Hodgkins PS, Wu HQ, Zielke HR, Schwarcz R (1999) 2-Oxoacids regulate kynurenic acid production in the rat brain: studies in vitro and in vivo. J Neurochem 72:643-651.

Kovalenko T, Osadchenko I, Nikonenko A, Lushnikova I, Voronin K, Nikonenko I, Muller D, Skibo G (2006) Ischemia-induced modifications in hippocampal CA1 stratum radiatum excitatory synapses. Hippocampus 16:814-825.

Lein PJ, Barnhart CD, Pessah IN (2011) Acute hippocampal slice preparation and hippocampal slice cultures. Methods Mol Biol 758:115-134.

Lundgaard I, Li B, Xie L, Kang H, Sanggaard S, Haswell JD, Sun W, Goldman S, Blekot S, Nielsen M, Takano T, Deane R, Nedergaard M (2015) Direct neuronal glucose uptake heralds activitydependent increases in cerebral metabolism. Nature communications 6:6807.

Miller JM, MacGarvey U, Beal MF (1992) The effect of peripheral loading with kynurenine and probenecid on extracellular striatal kynurenic acid concentrations. Neurosci Lett 146:115118.

Moroni F, Russi P, Lombardi G, Beni M, Carla V (1988) Presence of kynurenic acid in the mammalian brain. J Neurochem 51:177-180.

Nematollahi A, Sun G, Jayawickrama GS, Church WB (2016) Kynurenine Aminotransferase Isozyme Inhibitors: A Review. International journal of molecular sciences 17.

Okuno A, Fukuwatari T, Shibata K (2011) High tryptophan diet reduces extracellular dopamine release via kynurenic acid production in rat striatum. J Neurochem 118:796-805.

Olsson SK, Larsson MK, Erhardt S (2012) Subchronic elevation of brain kynurenic acid augments amphetamine-induced locomotor response in mice. J Neural Transm (Vienna) 119:155-163.

Potter MC, Elmer GI, Bergeron R, Albuquerque EX, Guidetti P, Wu HQ, Schwarcz R (2010) Reduction of endogenous kynurenic acid formation enhances extracellular glutamate, hippocampal plasticity, and cognitive behavior. Neuropsychopharmacology 35:1734-1742.

Prescott C, Weeks AM, Staley KJ, Partin KM (2006) Kynurenic acid has a dual action on AMPA receptor responses. Neurosci Lett 402:108-112.

Rosenthal N, Brown S (2007) The mouse ascending: perspectives for human-disease models. Nature cell biology 9:993-999.

Scharfman HE, Hodgkins PS, Lee SC, Schwarcz R (1999) Quantitative differences in the effects of de novo produced and exogenous kynurenic acid in rat brain slices. Neurosci Lett 274:111-114. 
Schwieler L, Erhardt S, Nilsson L, Linderholm K, Engberg G (2006) Effects of COX-1 and COX-2 inhibitors on the firing of rat midbrain dopaminergic neurons--possible involvement of endogenous kynurenic acid. Synapse 59:290-298.

Swartz KJ, During MJ, Freese A, Beal MF (1990) Cerebral synthesis and release of kynurenic acid: an endogenous antagonist of excitatory amino acid receptors. J Neurosci 10:2965-2973.

Turski WA, Gramsbergen JB, Traitler H, Schwarcz R (1989) Rat brain slices produce and liberate kynurenic acid upon exposure to L-kynurenine. J Neurochem 52:1629-1636.

Urbanska EM, Chmielewski M, Kocki T, Turski WA (2000) Formation of endogenous glutamatergic receptors antagonist kynurenic acid--differences between cortical and spinal cord slices. Brain Res 878:210-212.

Vecsei L, Szalardy L, Fulop F, Toldi J (2013) Kynurenines in the CNS: recent advances and new questions. Nature reviews Drug discovery 12:64-82.

Zmarowski A, Wu HQ, Brooks JM, Potter MC, Pellicciari R, Schwarcz R, Bruno JP (2009) Astrocytederived kynurenic acid modulates basal and evoked cortical acetylcholine release. Eur J Neurosci 29:529-538. 
Fig. 1: Glucose consumption in the course of $4 \mathrm{~h} \mathrm{SV}$ incubation. Acute slices were incubated as routinely in aCSF having high glucose concentration (10mM). Glucose concentration was already dropped after $30 \mathrm{~min}(\approx 8 \%)$, however, the decrease was not statistically significant $(\mathrm{F}=4,281 ; \mathrm{p}=0,072 ;$ Partial Eta Squared: 0,349). 4h incubation, however, resulted in a significant decrease of aCSF glucose content $(\approx 20 \%) \quad(\mathrm{F}=20,304$; $p=0,002$; Partial Eta Squared: 0,717). Data are expressed as a percentage of baseline glucose content (glucose content of the aCSF at the starting point of the experiment) and represent the mean \pm SD. $n=5$ animals, $6+6$ corresponding brain slices per condition.

Fig. 2: LDH release in the course of $4 \mathrm{~h} \mathrm{SV}$ incubation. At the beginning of the incubation aCSF LDH content is virtually zero (only measuring error is depicted). In comparison, gradual increase of the aCSF LDH content could be measured in the course of $30 \mathrm{~min}(\mathrm{Z}=$ $16,910 ; p=0,959)$ and $4 \mathrm{~h}$ incubation $(Z=16,910 ; p=0,030)$. However Triton $X-100$ treatment resulted in a $\approx 14$ fold increase of $\mathrm{LDH}$ in the aCSF after $4 \mathrm{~h}(\mathrm{Z}=16,910 ; \mathrm{p}=0,001)$. This indicates that the cell membrane integrity is largely preserved in the case of $4 \mathrm{~h}$ incubation. Data represent the mean \pm SD. $n=9$ animals, $6+6$ corresponding brain slices per condition.

Fig. 3: Cresyl violet staining (A-B) and NeuN immunolabelling (C-D) in the dorsal hippocampus of mouse acute brain slices. There was no visible difference between the LV (A-C) and SV (B-D) group in the CA1 area of the hippocampus after 4h incubation. Cells keep their normal appearing in the pyramidal cell layer. Scale bars are $100 \mu \mathrm{m}$.

Fig. 4: Basal glutamatergic synaptic properties of acute brain slices. There is no significant difference between slices recorded immediately after post-slicing recovery period (30 min.), or incubated under LV condition for 4hours and under SV conditions, respectively $(\mathrm{F}=0.793 ; \mathrm{p}=0,465$; Partial Eta Squared: 0,064$)$. The values represent normalized means $\pm \mathrm{SD}$ and were plotted as a function of stimulus strength. $\mathrm{n}=17$ animals; $11+9+8$ recordings/group.

Fig. 5: Basal and de novo KYNA content in the incubating aCSF and in the tissue homogenate after $4 \mathrm{~h}$ incubation. Without L-KYN administration $7.01 \pm 2.03 \mathrm{ng}$ basal KYNA content could be measured from the aCSF and $0.22 \pm 0.07 \mathrm{ng}$ from the brain tissue homogenate. In contrast, as a result of $10 \mu \mathrm{M}$ L-KYN administration we found a 6.3 fold increase in the aCSF $(44.56 \pm 6,99 n g)(Z=6,818 ; p=0,009)$ and a 3.8 fold increase in the tissue $(0.85 \pm 0.21 \mathrm{ng})$ KYNA content. The values represent means \pm SD. $n=5$ animals, $6+6$ corresponding brain slices per condition.

Fig. 6: Effect of KAT-2 inhibitor PF-04859989 on de novo KYNA release. Acute slices were incubated in the presence of $10 \mu \mathrm{M}$ L-KYN with or without PF-04859989 in a concentration of $5 \mu \mathrm{M}$. KYNA content of the aCSF was measured after $4 \mathrm{~h}$ incubation. High KYNA content could be measured in the L-KYN group (55.19 $\pm 6.45 \mathrm{ng}$ ). Addition of the inhibitor resulted in a significant decrease of the released KYNA in the aCSF by almost $40 \%$ (34.5 $\pm 6.93 \mathrm{ng} ; \mathrm{F}=23,868 ; \mathrm{p}=0,001 ;$ Partial Eta Squared: 0,749). The values represent 


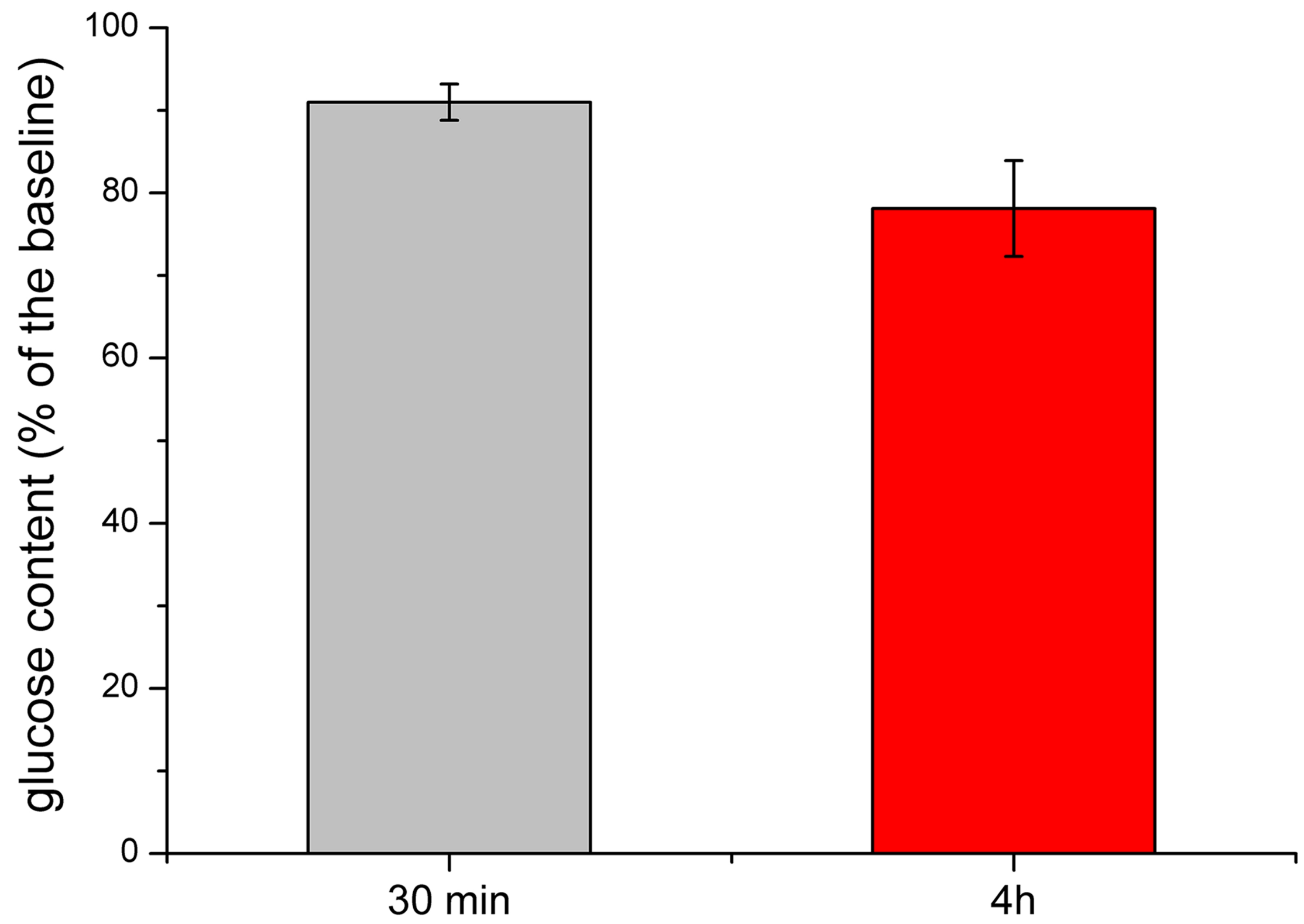




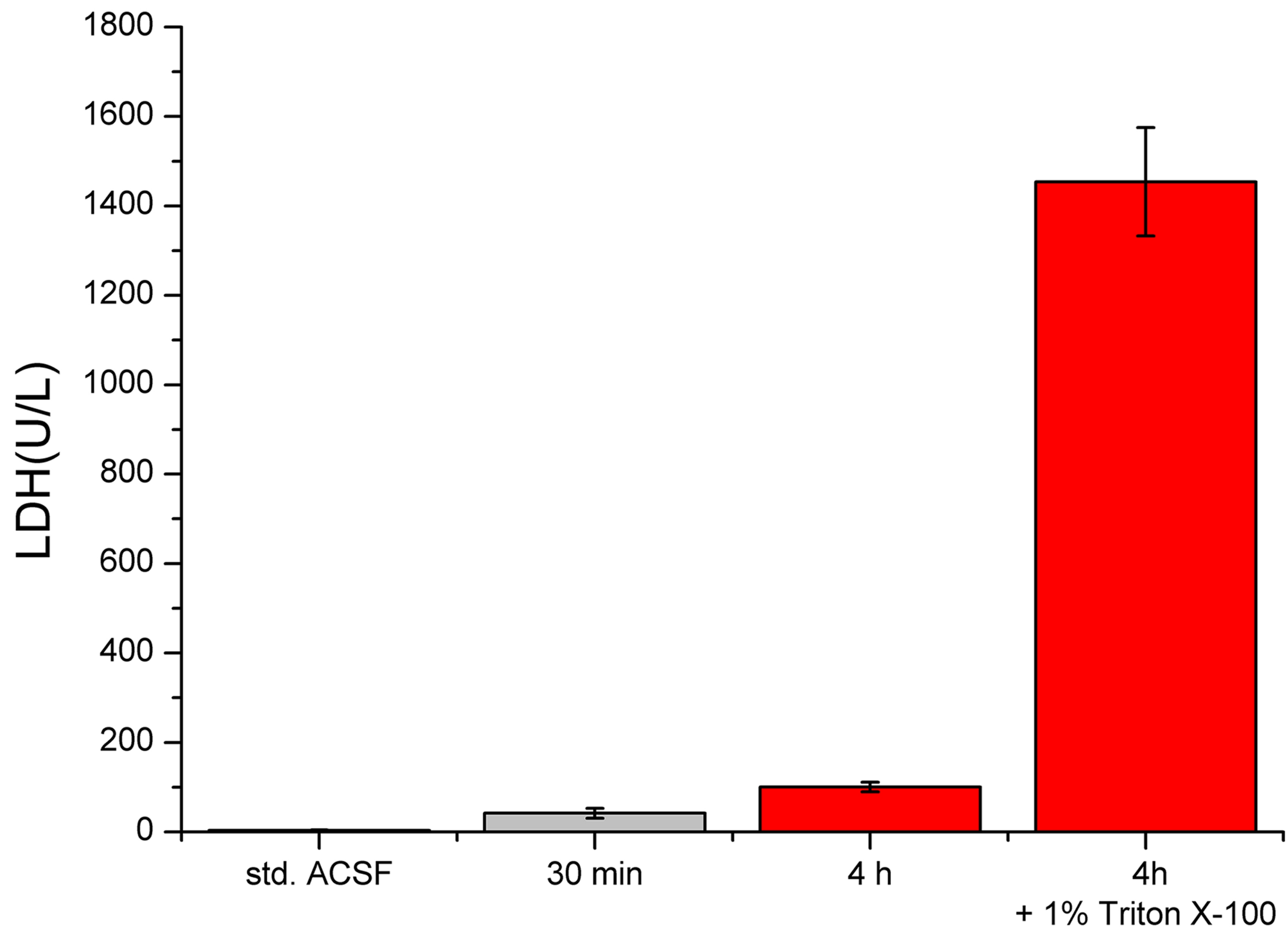




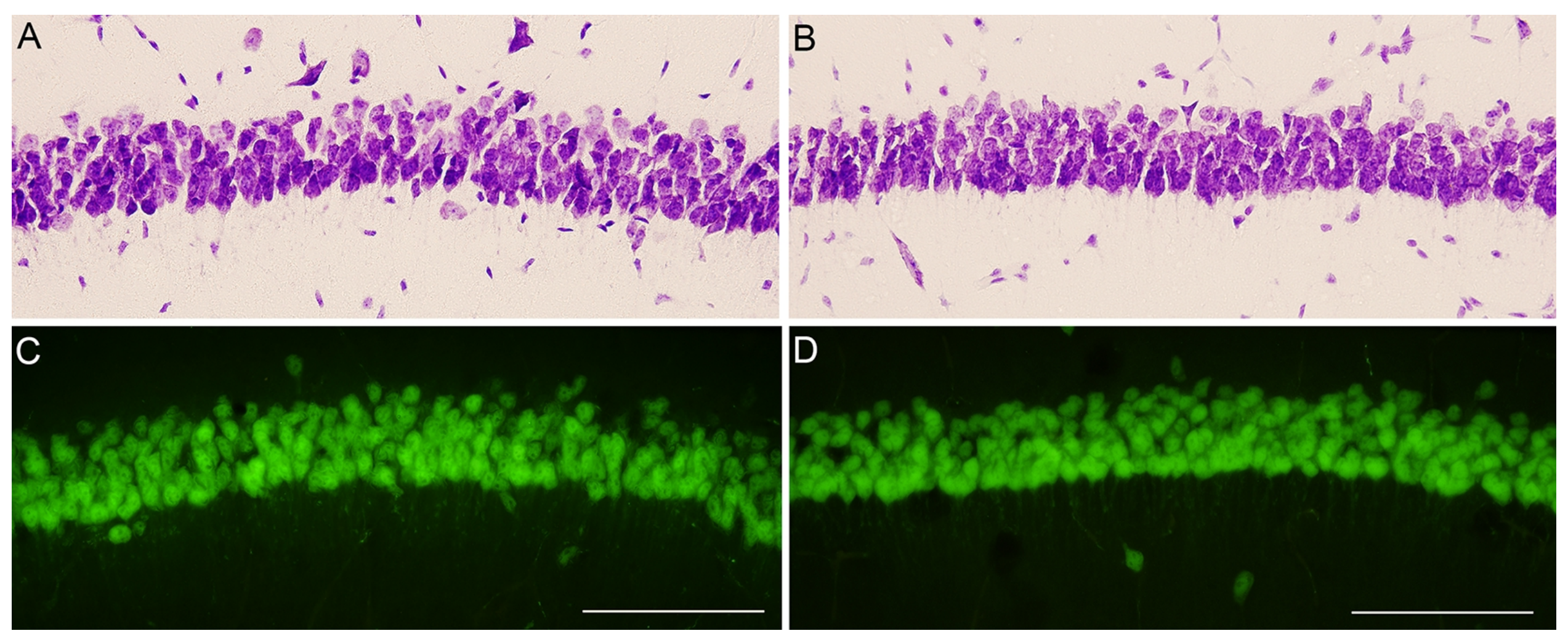




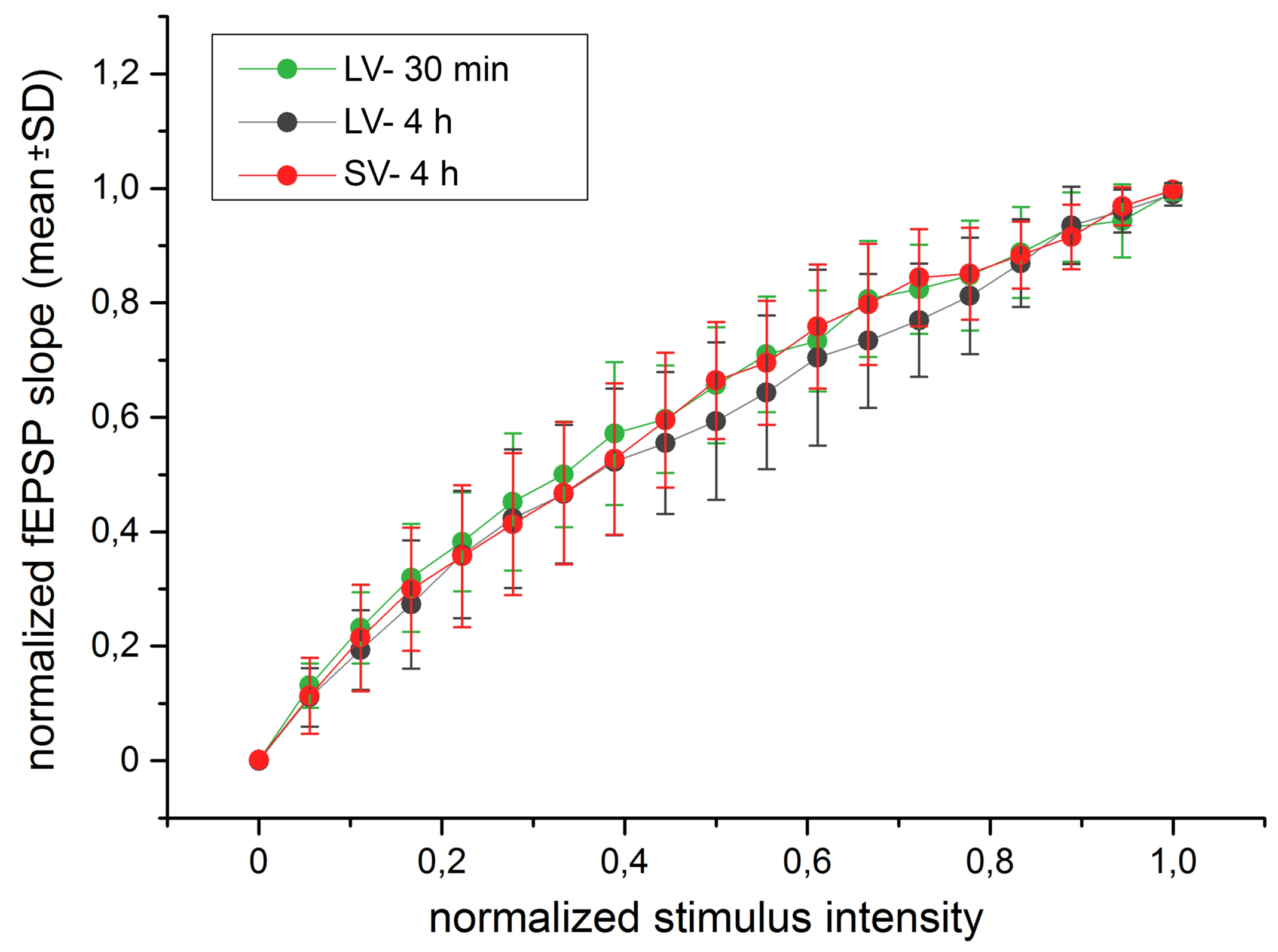




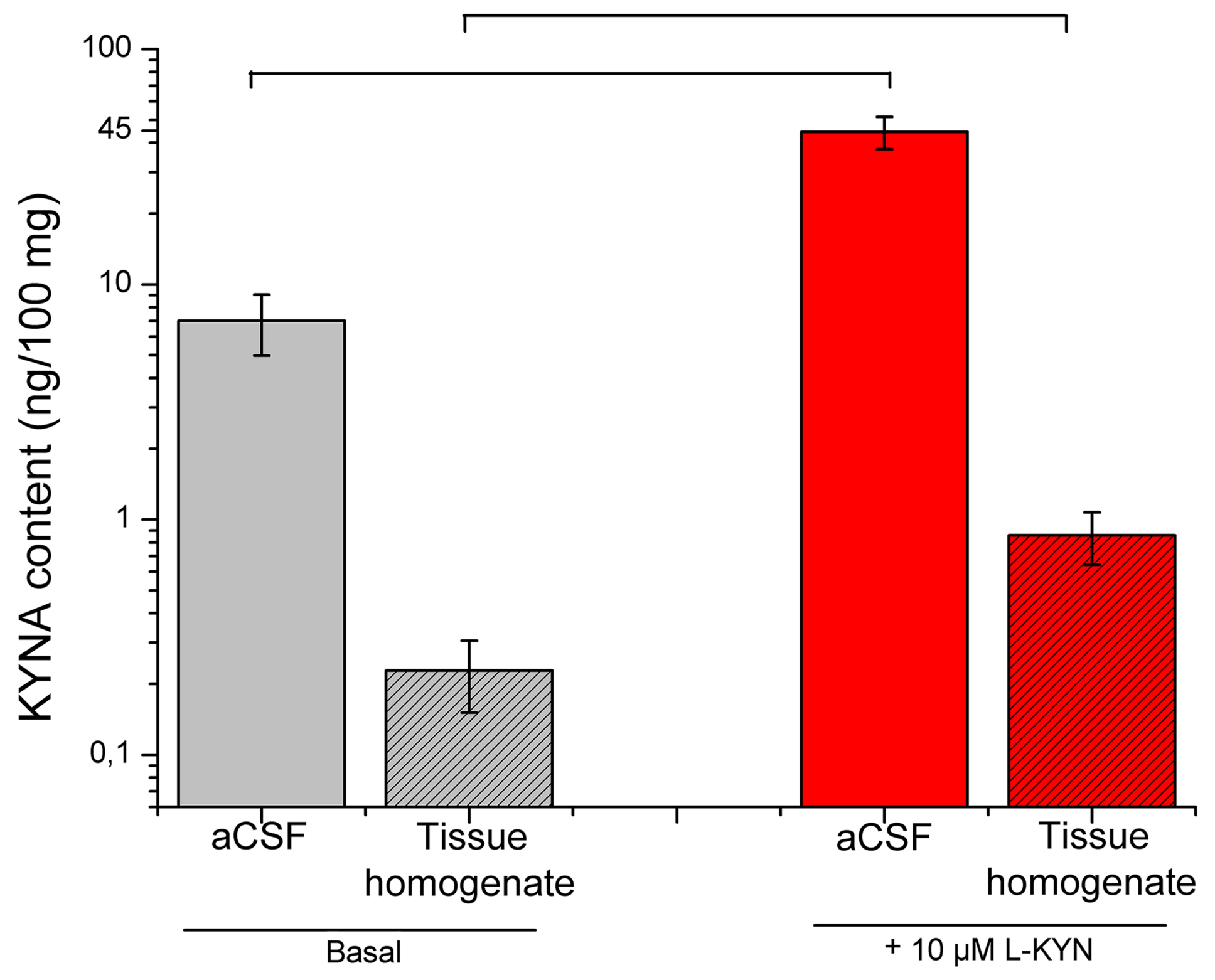




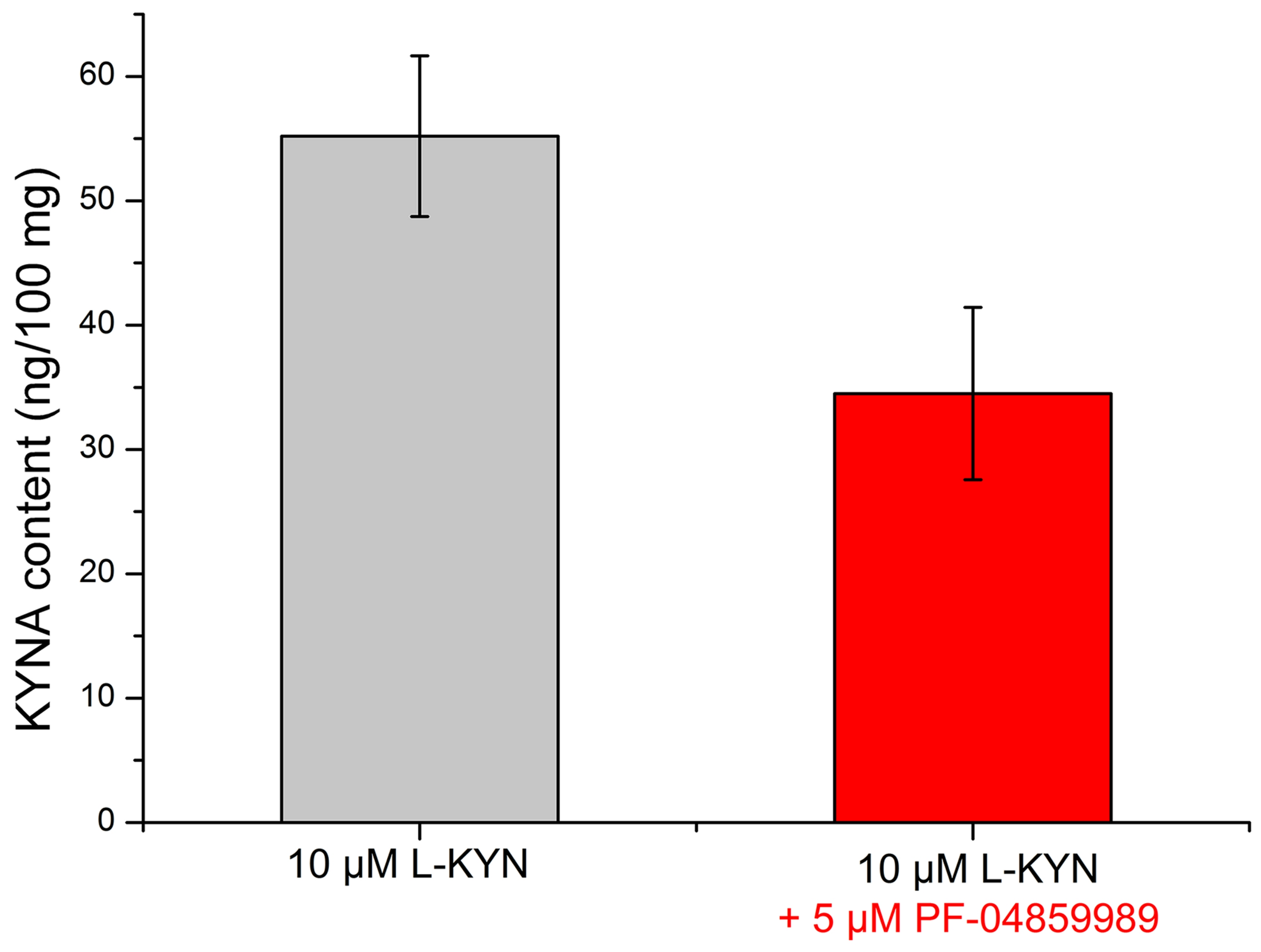




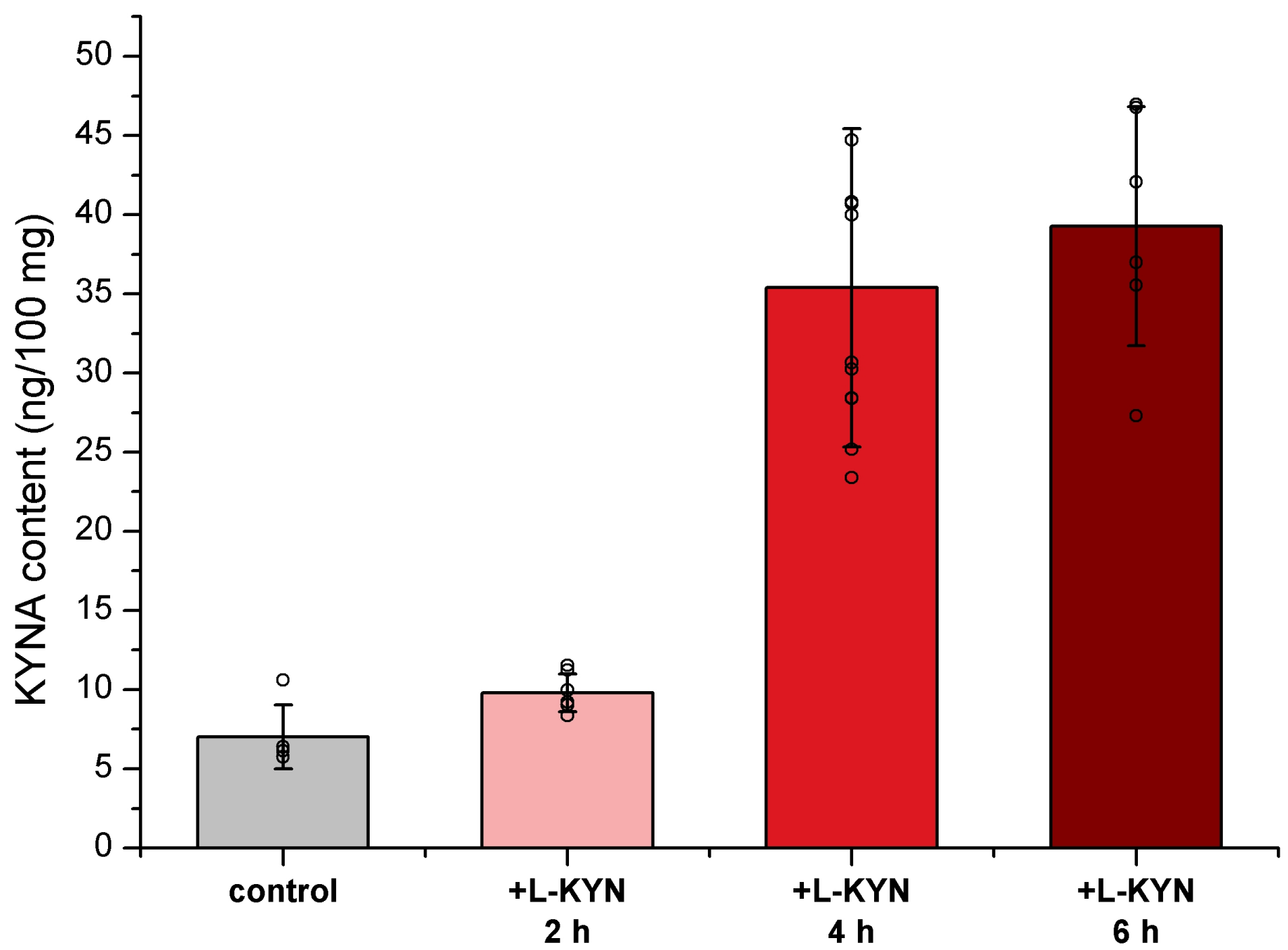




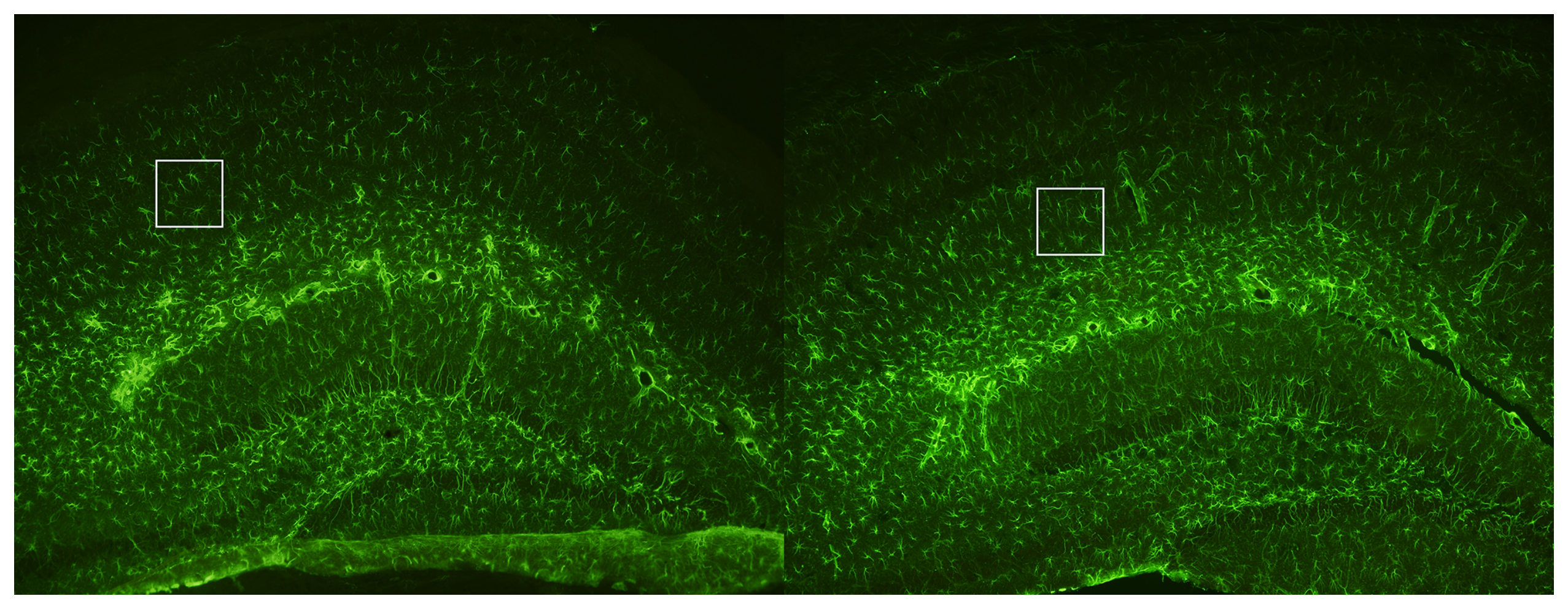




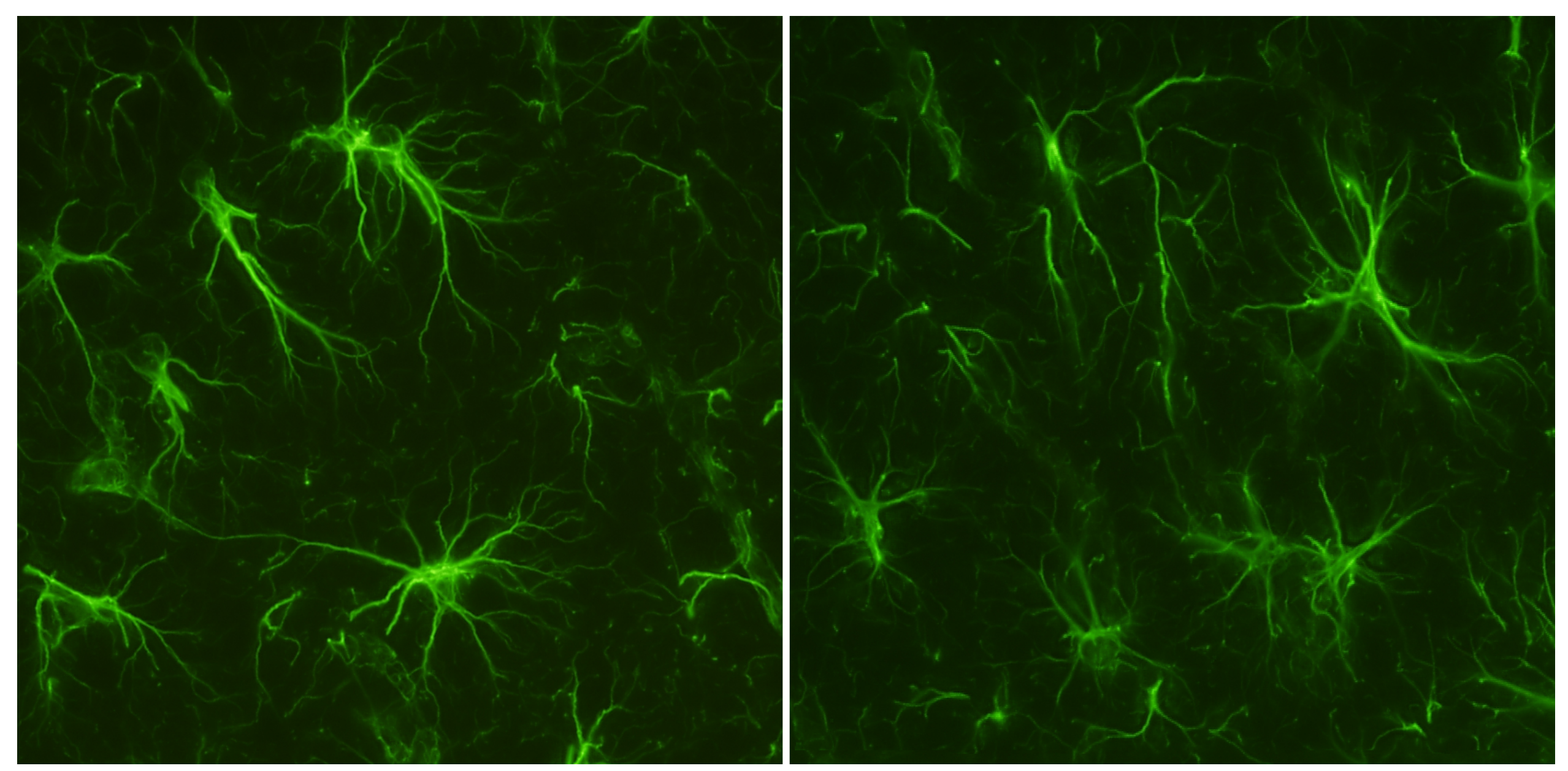




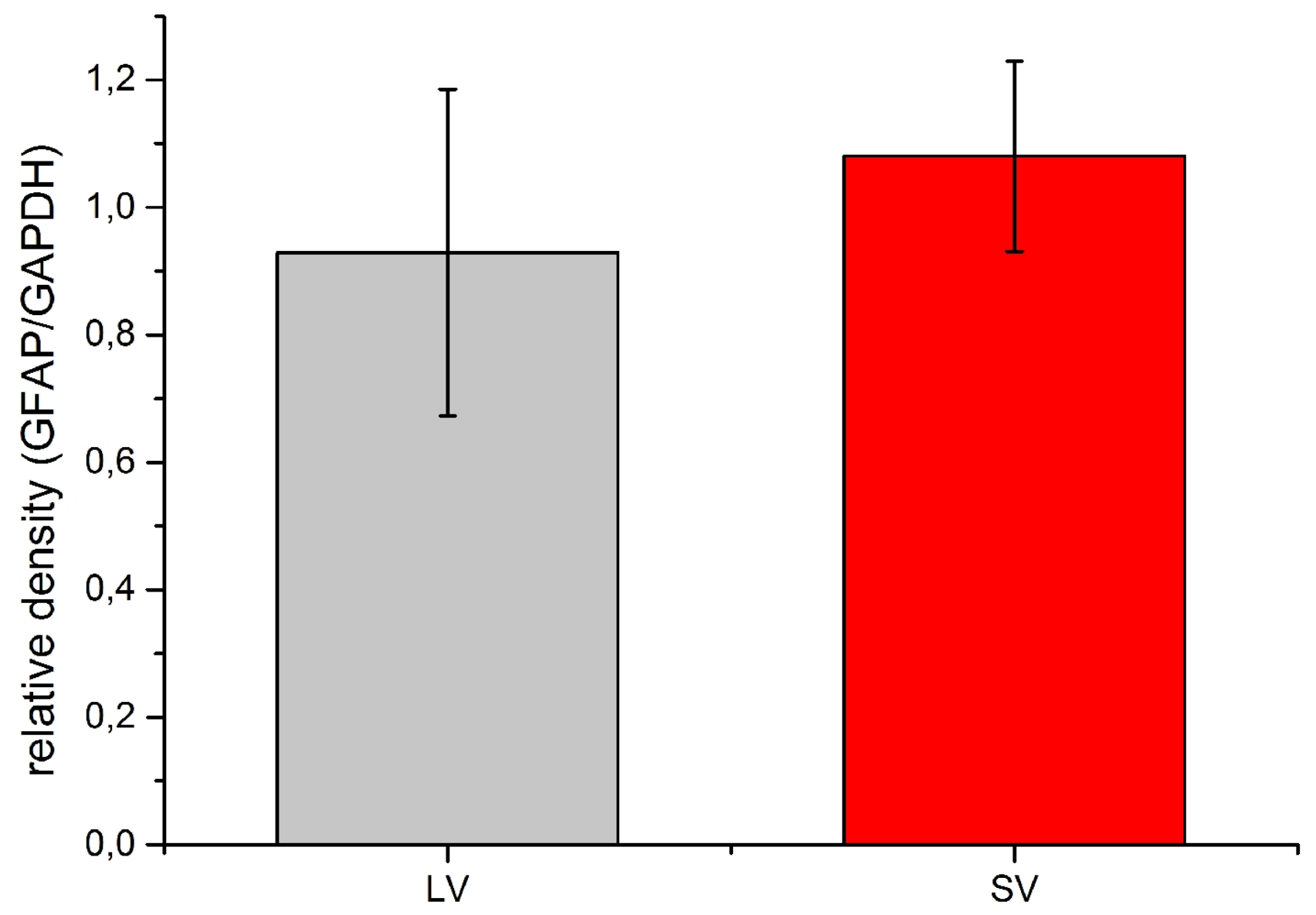

GFAP

GAPDH 